\title{
A survey of rift valley fever and associated risk factors among the one-humped camel (Camelus dromedaries) in Sudan
}

\author{
Maiy M. M. Abdallah', Ibrahim A. Adam¹, Tamadur M. Abdalla', Sanaa A. Abdelaziz', Mohamed E. Ahmed² \\ and Imadeldin E. Aradaib ${ }^{1 *}$
}

\begin{abstract}
Background: Rift valley fever (RVF) is a mosquito-borne viral disease of domestic livestock and wild ruminants. In camels RVF may cause abortion among pregnant camels, but is most often asymptomatic among other camels. In this study, a seroepidemiological survey was conducted to determine the prevalence of RVFV antibodies and to identify the potential risk factors associated with RVFV seropositivity among the Sudanese one-humped camel (Camelus dromedaries) in Khartoum State, Sudan. A cross sectional study was conducted in Khartoum State, Sudan, in a total of 240 camels selected randomly from four localities. Sera sampled were tested for the presence of RVFV-specific immunoglobulin $\mathrm{G}(\mathrm{lgG})$ antibodies using a competitive enzyme-linked immunosorbent assay (c-ELISA).

Results: RVFV seropositivity was recorded in 23 out of 240 animals, prevalence rate of $9.6 \%$ among camels in Khartoum State. Age $(\mathrm{OR}=8.29, p$-value $=0.04)$ and heavy rainfall $(\mathrm{OR}=5.36, p$ value $=0.01)$ were recorded as potential risk factors for contracting RVF.

Conclusions: Older age and heavy rainfall were considered as potential risk factors for seropositivity to RVF. Surveillance for RVF among camels and distribution of mosquito vectors should continue to better understand the clinical signs associated with RVFV infection in camels and provide public health authorities an opportunity to anticipate and prepare for a possible RVF outbreak in Khartoum State, Sudan.
\end{abstract}

Keywords: Epidemiology, Survey, Camels, RVF, cELISA, Sudan

\section{Background}

Rift Valley fever (RVF) is a mosquito-borne viral disease that typically occurs in various areas of sub-Saharan Africa, where virus activity varies from a low-level enzootic cycle to explosive outbreaks covering large areas [1]. RVF is caused by RVF virus (RVFV), a member of the phlebovirus genus in the family Bunyaviridae. Periodically, RVFV spreads to other areas, including northward into Egypt in 1977 and eastward across the Red Sea into Saudi Arabia and Yemen in 2000 [2-6]. RVF in livestock can be devastating to agricultural communities and causes almost fatal clinical disease among young animals and high abortion rates among livestock

\footnotetext{
* Correspondence: aradaib@yahoo.com; aradaib@uofk.edu

${ }^{1}$ Molecular Biology Laboratory (MBL), Department of Clinical Medicine, Faculty of Veterinary Medicine, University of Khartoum, P.O. Box 32, Khartoum North, Sudan

Full list of author information is available at the end of the article
}

[7]. In contrast, RVF is asymptomatic in humans and can cause a mild febrile illness. Few cases (1-2 \%) progress to more severe disease, such as acute hepatitis, encephalitis, retinitis and/or a hemorrhagic syndrome [8]. The first outbreak of RVF in Sudan was reported in 1973 among sheep and cattle in the White Nile State [9]. Subsequently, RVFV was isolated from a herd of cattle in Hilat Kuku, Khartoum North $[9,10]$. Serologic surveys have detected RVFV antibodies in various species of domestic livestock and in humans from different States of the Sudan, including Nile Valley, Khartoum, Kassala, El Gezira, Sennar, and White Nile [1, 11-15]. A recent seroepidemiologic survey reported a high prevalence of RVFV IgG among febrile patients admitted to New Halfa Hospital in Kassala State, Sudan [16]. New Halfa is an extensively irrigated agricultural province, located approximately $500 \mathrm{~km}$ east of Khartoum 
State. The high prevalence of RVFV- specific IgG antibodies suggested considerable circulation of RVFV in Kassala State at a particular point in time in the past.

Currently, little is known about the prevalence of RVF in livestock in Sudan and no information is available in regard to the potential risk factors associated with RVF among the livestock in the country, including the Sudanese dromedary camels. Circulation of RVFV in camels and detection of RVFV-specific antibodies is well documented in the different region of the African continent, including Sudan, Saudi Arabia, Tanzania, South Africa, Mauritania, Kenya, Niger and Nigeria [7, 17-27]. Thus, during RVFV infection, viremic camels can provide virus for vector transmission to humans and highly susceptible young ruminants, particularly lambs $[24,28]$. In addition, previously employed techniques for the detection of RVFV antibodies in Sudanese camels includes agar gel immunodiffusion test, which is far less sensitive than ELISA assay and is complicated by cross reaction with other phleboviruses. Therefore, the control of RVF would be important in the Sudan given the large numbers of camels in the country, and their importance to the national economy and rural communities [1]. Most of the existing data about the epidemiology of RVF in camels in the Sudan is old. We believe epidemiologic studies, including implementation of improved surveillance, are urgently needed to better predict and respond to RVF outbreak among camels in the Sudan. The objectives of the present study were to estimate the prevalence of RVF, as determined by detection of RVF-specific IgG antibodies, and to identify the potential risk factors associated with the diseases among the onehumped camel (Camelus dromedarius) in Khartoum State, Sudan. This study would be expected to reduce the impact on the livelihood of pastoral communities and ultimately avoid disease spread in human population.

\section{Methods}

\section{Study area}

The study was conducted in Khartoum State during the period from October 2014 to March 2015. The State covers an area of approximately 20,971 square kilometers. The State is located between latitudes $15^{\circ} 8^{\circ}-16^{\circ} 39^{\circ} \mathrm{N}$ and longitudes $31^{\circ} 36-34^{\circ} 25 \mathrm{E}$ in the semi desert tropics. It is dominated by semi desert climate, which is characterized by very hot/dry summer and cold winter. The average temperature ranges from $21^{\circ} \mathrm{C}$ in the winter to $47{ }^{\circ} \mathrm{C}$ in the summer. The mean annual evaporation rate is $7.7 \mathrm{~mm} /$ day, and the average relative humidity ranges from $21 \%$ to $-38 \%$. Khartoum State is boarded by the River Nile State in the north; Kassala States in the east, North Kordufan in the west and Elgezera State to the South. The total population of camels in the country is approximately 4.6 million. The camel population of
Khartoum State is 6,585 as estimated by the Sudan Ministry of Animal Resources, 2006. A map of the localities included in the study area of Khartoum State is presented in (Fig. 1).

\section{Study design}

A cross sectional study was conducted to estimate the prevalence rate of RVFV-specific IgG antibodies in camels and to investigate the potential risk factors associated with the disease. A total of 240 camels were selected randomly using multistage probability sampling method. Four localities were randomly selected from all seven localities in Khartoum State, Sudan, which include, Um Badah, Omdurman, Sherq Elnile and Bahri. Two administration units were selected randomly from each locality. Finally, simple random sampling was applied to choose the animals from each herd [29]. All camels included in this study were aged over one year. The study is reported in compliance with the STROBE statement [30].

\section{Questionnaire}

A pre-tested structured questionnaire with the primary objective of elucidating the multifactorial background of disease was conducted in an interactive manner at all selected herds. All animals included in this study were subjected to a questionnaire, which was filled out by the animal owners. The questionnaire include individual risk factor attributes including age (younger animals $<2$ years, older animals 2 years and above), sex (male, female), breed (Anafi, western), body condition (emaciate, fat), and management risk factor attributes including herd size (small, medium, large), grazing system (nomadic, semi-nomadic, stationary), rain fall (high, low), mosquito vector (presence or absence), mosquito control (practiced or not), vegetation (low, high), water bonds (presence or absence), and the four localities included in the study.

\section{Collection of blood samples}

A total of 240 blood samples were collected from the dromedary camels in the study area of Khartoum State, Sudan. Serum samples were separated and were kept frozen at $-20{ }^{\circ} \mathrm{C}$ for detection of RVFV-specific IgG antibodies using competitive enzyme-linked immunosorbent assay (cELISA).

\section{Competitive Enzyme-Linked Immunosorbent Assay (cELISA)}

A competitive enzyme-linked immunosorbent assay (cELISA) was performed, as described by Hassanain et al. [16], using a commercially available RVFV antibody cELISA Kit (IDVet, Rue Louis Pasteur, Grabels, France). The sera were screened for RVFV-specific IgG antibodies as described by the manufacturer's specifications. cELISA was performed in 96-well antigen-coated 


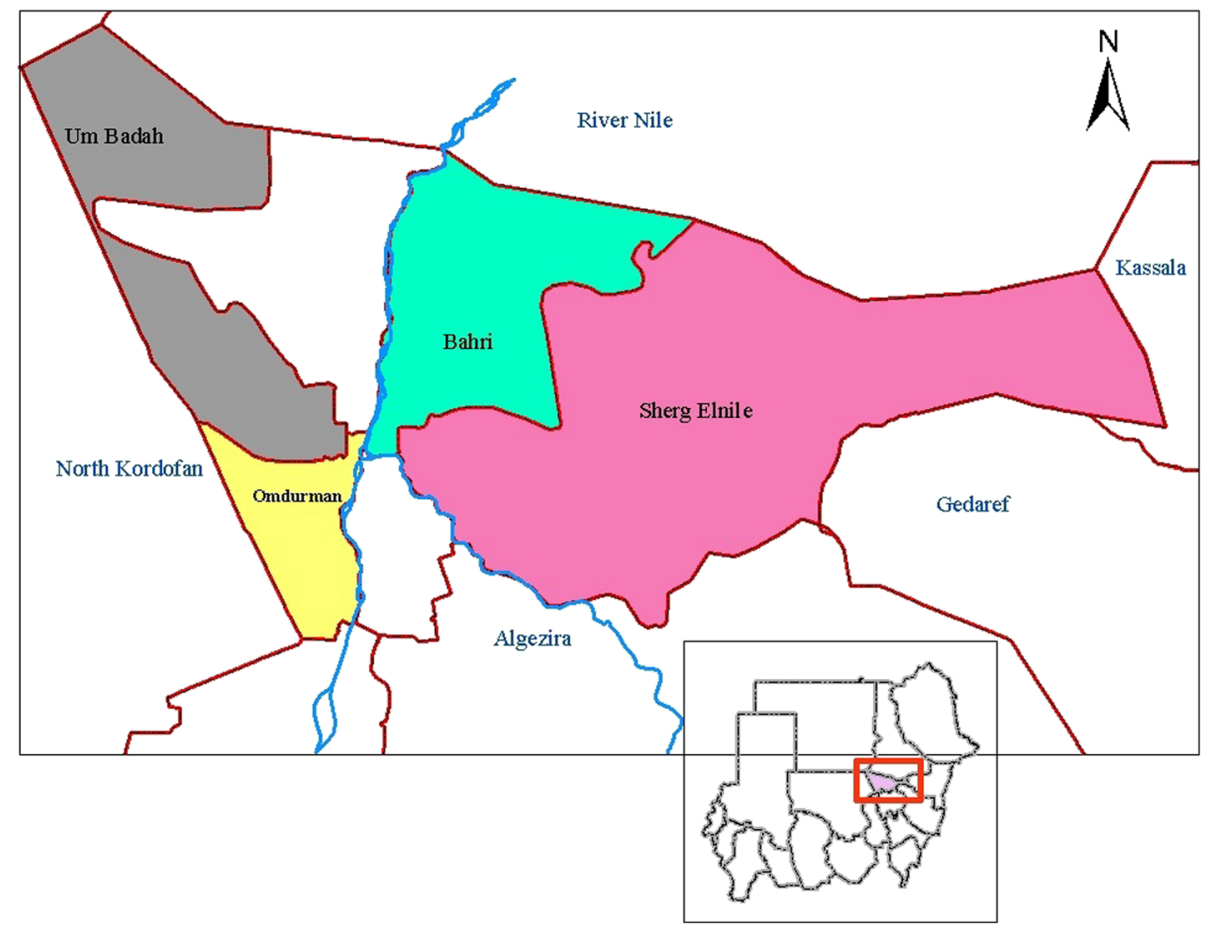

Fig. 1 Map of State of Khartoum, Sudan showing the four localities included in the study

microplates. Unless stated otherwise, 50 microliters $(\mu \mathrm{l})$ test volumes were used in the cELISA assay. The incubations were performed for $15 \mathrm{~min}$ at room temperature $\left(23 \pm 2{ }^{\circ} \mathrm{C}\right)$. The plates were washed three times with the provided washing buffer. Briefly, aliquots of $50 \mu \mathrm{l}$ test sera as well as positive and negative controls sera were transferred undiluted to the RVFV antigen coated plates, using multi-channel pipette. After incubation, the plates were washed, and $50 \mu \mathrm{l}$ of antibody-peroxidase conjugate were added to each well. The plate was incubated at $15 \mathrm{~min}$ at room temperature. The plates were then washed and $50 \mu \mathrm{l}$ the substrate was added to each well. The reaction was stopped using $50 \mu \mathrm{l}$ of the stopping solution. The results were read by using ELISA reader set at $450 \mathrm{~nm}$. A presumptive diagnosis was made when the test samples produced an optical density $<50 \%$ of the mean of the negative controls. The test samples were considered negative if the optical density $\geq 50 \%$ of the mean of the negative controls.

\section{Statistical analyses}

The data collected were entered into a computer on a Microsoft Excel spread sheet. Statistical analysis was performed using SPSS version 16 (for Windows) and double checked before analyses. Associations between the outcome variable (status of RVF seropositivity in camels) and its potential risk factors were first screened in a univariable analysis using Chi-square $\left(x^{2}\right)$ test. A multivariable model for the outcome variable was constructed using logistic regression analysis with enter method for modeling checking. RVF was considered as the dependent variable and the risk factors as independent variables. Finally, odd ratios and $95 \%$ confidence interval $(\mathrm{CI})$ were calculated, and risk factors with a $p$-value $<0.05$ were taken as significant association to RVF seropositivity.

\section{Results}

Using a cELISA assay, RVFV-specific IgG antibodies were detected in 23 out of 240 camels included in the study. The overall prevalence rate of RVFV antibodies among camels in Khartoum State of Sudan was estimated to be $9.6 \%$. The highest and lowest rates of RVFV seropositivity were recorded in Sherq Elnile and Omdurman, respectively. The results of the univariate analysis using chi-square test were presented in (Table 1). The final model of RVFV infection indicated that only two independent risk factors were statistically significant. Older cattle ( $>2$ years of age) were eight times more likely to have been infected with RVF $(\mathrm{OR}=8.29, \mathrm{CI}=1.05-9.66$, $p$-value $=0.04)$ compared to young animals $(<2$ years of age). Heavy rainfall increased the risk of contracting RVF compared to low rainfall $(\mathrm{OR}=5.36, \mathrm{CI}=1.46-19.66$, $p$ value $=0.01)$. Significant association between RVF and potential risk factors in the final model were shown in (Table 2). In contrast, there was no significant 
Table 1 Univariate analysis for the association between potential risk factors and RVF seropositivity among camels in Khartoum State of Sudan using Chi-square test

\begin{tabular}{|c|c|c|c|c|c|c|c|c|c|c|c|}
\hline Risk factors & $\begin{array}{l}\text { Animals } \\
\text { tested }\end{array}$ & $\begin{array}{l}\text { Animals affected } \\
(\%)\end{array}$ & $d f$ & $x^{2}$ & $p$-value & Water bond & & & 1 & 0.18 & 0.13 \\
\hline Locality & & & 3 & 0.48 & 0.37 & No & 125 & 15 (12 \%) & & & \\
\hline East Nile & 60 & $8(13.3 \%)$ & & & & Yes & 115 & 8 (7 \%) & & & \\
\hline
\end{tabular}

\section{Bahry}

Omdurman

60

Ombadda

60

$4(6.7 \%)$

Age

Small

Old

Sex

Female

Male

Breed

Western

Anafi

Bushari

Body condition

Emaciation

Thin

Fat

Farm yard

In door

Out door

Grazing system

Stationary

Nomadic

Herd size

Small

Large

Mosquitoes present

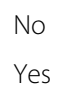

Yes

Mosquitoes control

$$
\begin{aligned}
& \text { No } \\
& \text { Yes }
\end{aligned}
$$

Rain fall

Low

High

Vegetation

Low

High

\section{0}

$$
4(6.7 \%)
$$

53

1 (1.9\%)

$19 \quad 1(5.3 \%)$

$105 \quad 10(9.5)$

3

7 (8.5 \%)

126

114

$7(6.1 \%)$

59

$5(8.5 \%)$

$2(7.1 \%)$

$1(5.3 \%)$

193

\section{4}

156

4 (4.8\%)

193

47

$4(8.5 \%)$

$3(3.2 \%)$

116
$7(11.7 \%)$

$3(7.9 \%)$

$22(11.8 \%)$

$20(9.9 \%)$

$116 \quad 12(10.3 \%)$

$1(33.3 \%)$

$155 \quad 15(9.7)$

16 (12.7\%)

$18(9.9 \%)$

$20(10.4 \%)$

$19(12.2 \%)$

19 (9.8\%)

$20(13.6 \%)$

$14(11.3 \%)$ $\begin{array}{lll}1 & 0.70 & 0.48\end{array}$

$\begin{array}{lll}2 & 0.78 & 0.82\end{array}$

$\begin{array}{lll}1 & 0.03 & 0.031\end{array}$

$\begin{array}{lll}2 & 0.35 & 0.80\end{array}$

$1 \quad 0.085 \quad 0.065$

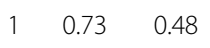

$2 \quad 0.69 \quad 0.47$

$\begin{array}{lll}1 & 0.063 & 0.047\end{array}$

$1 \quad 0.78 \quad 0.518$

$1 \quad 0.008 \quad 0.005$

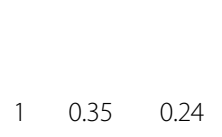

Table 1 Univariate analysis for the association between potential risk factors and RVF seropositivity among camels in Khartoum State of Sudan using Chi-square test (Continued)

association between RVF seropositive camels and the animal sex, breed, grazing system, mosquito control, herd size, body condition, introduction of new animal to the herd, and localities.

\section{Discussion}

In recent years, the distribution and nature of RVF has changed substantially. RVF has become of great veterinary concern to dairy producers, wildlife managers and veterinary diagnosticians because of the frequent occurrence of sporadic cases and outbreaks among domestic and wild ruminants [1, 3, 5, 31-33]. Very little information is available about the epidemiology and disease potential of RVF in domestic livestock of the Sudan. The prominent clinical sign in RFV infected camel is mainly reflected by abortion storm [9]. Absence of clinically recognized symptoms of RVF infections with noticeable outbreaks of abortion may lead to underestimation of the importance of the disease in Sudanese camels. In contrast, clinical signs other than abortions were reported among camels in RVF outbreak in Mauritania, including hemorrhagic septicemia and severe respiratory distress [26]. This observation indicated that the pathogenicity of RVFV in the dromedary camels has not been investigated sufficiently. To advance beyond the current knowledge of the epidemiology of the disease, we conducted this study to determine the prevalence of RVF and associated risk factors among camels in Khartoum, Sudan, the second largest producing camel region in the world.

In epidemiological surveys, high prevalence rates of $45 \%$ and $38.5 \%$ for RVFV seropositivity were reported among camels in Tanzania and Mauritania, respectively $[26,27]$. In Niger, high prevalence rate of RVFV

Table 2 Multivariate analysis, using logistic regression model, for significant association ( $p>0.05$ ) of risk factors and RVF seropositivity among camels in Khartoum State, Sudan

\begin{tabular}{llll}
\hline Risk factors & OR & $95 \% \mathrm{Cl}$ & $P$-Value \\
\hline Age & & & \\
Small & Reference & $1.05-9.65 .35$ & 0.04 \\
Old & 8.29 & & \\
Rain fall & & & 0.01 \\
Low & Reference & $1.46-19.66$ & \\
Heavy & 5.36 & & \\
\hline
\end{tabular}


seropositivity of $47.5 \%$ was also reported in camels in some region of the country [34]. In Nigeria, earlier serological surveys indicated that RVF infection is generally widespread among camels with a prevalence rate of $3.3 \%$ [19]. In the present study, the seroprevalence of RVFV-specific antibodies in camels of Khartoum State $(9.6 \%)$ is markedly higher than previously reported prevalence rates in other states of Sudan [12]. The high seroprevalence rate of RVFV in Khartoum could be attributed to newly constructed irrigation projects and agricultural scheme in the region, which might contribute in suitable climatic condition for survival of the adults and larvae of Aedes vectors in this region $[35,36]$. In addition, the heavy rainfall associated with the large RVF outbreaks in Sudan 2007 and 2010 were suggested to contribute to high prevalence of RVF among the Sudanese dromedary camel $[1,28]$. The circulation of RVFV in the country and the risks these infected camels pose for highly susceptible young ruminants necessitates the importance of improved surveillance system for this viral pathogen in Sudan. The RVF seropositivity increased with older age in the studied herds. When assessing age as a risk factor, there was a significant association between RVFV infection rate and increasing age of the animal. It was shown that the camels started to get infected with RVFV after the age of 2 years. At this age, the animals are usually released into the pasture for grazing, where they are likely to be exposed to infected mosquitoes and subsequent RFV infection. We believe that the association of RVF and age is probably attributed to frequent exposure of older camels to the mosquito vectors. Young camels ( $<2$ years) are usually kept indoors and are well taken care of by the animal owners from contracting infectious diseases, particularly the insect and tick-borne infections. Our result is in agreement with previous epidemiological surveys, which reported higher risks of older camels for RVF infections $[19,27,37]$. It should be noted that the RVFV-specific antibodies detected among camels in Khartoum State indicated natural infection as vaccination is not practiced in the country for this animal species. In addition, all camels included in this study were aged over one year. Therefore, it is assumed that maternal antibodies were no longer persisted and that antibody indicated natural infection with RVF.

Heavy rainfall is another potential risk factor that affects RVFV seropositivity among camels in Khartom State. Our result is in agreement with that of the study conducted by other workers who reported association between RVF seropositivity and rainfall $[24,25]$. The role of the international trade of livestock in dissemination of animal diseases should not be neglected. In this regard, live camels are exported to Egypt, from Sudan as a source of meat, for human consumption. Therefore, identification of the genetic lineage of RVFV strains circulating in a particular location would be important to follow the movement of the virus within and outside the African continent $[1,38-40]$.

In contrast, the risk assessment studies indicated that there was no significant association between RVF seropositivity and the rest of the individual or management risk factors included in the study. There was no significant difference between localities regarding RVF seropositivity in camels. In addition, there was no significant association between mosquito control and RVF seropositivity among camels suggesting failure of the control program against RVF in Khartoum State. Highest and lowest rates of RVFV infections were recorded in Sherq Elnile and Omdurman localities, respectively.

\section{Conclusions}

The study provides evidence of circulation of RVFV among camels in Khartoum State, Sudan, as determined by the presence of RVFV-specific IgG antibodies using cELISA. It is recommended that further study should be conducted in sentinel camel herds to determine the incidence of new cases and to conduct RVF virus isolation attempts. Any recovered RVFV strains should be employed to determine the virus whole genome sequence and to identify the genetic lineage of the virus circulating among camels in Khartoum State. Surveillance for RVF in domestic livestock and studies on distribution of the mosquito vectors should continue to provide public health authorities an opportunity to anticipate and prepare for a possible RVF outbreak in Khartoum State, Sudan.

\section{Acknowledgements \\ The technical assistance of Mr. Abdalla M. Fadlelmoula is gratefully acknowledged. The map of Khartoum State was produced by Dr. Shirin Elamin for which we are very thankful. This study received partial financial support from the Scientific Research Corporation of the Ministry of Higher Education and Scientific research, Khartoum, Sudan.}

\section{Authors' contributions}

MMA, IAA, and IEA designed the study. MMA, TMA, and SAA performed the laboratory work. IEA and MEA analyzed the data. All the authors shared in the drafting of the paper and all of them approved the paper.

\section{Competing interests}

The authors declare that they have no competing interests. The result of this study does not reflect the opinion of the funding sources. All authors have read and approved the final version of this manuscript.

\section{Ethics approval and consent to participate}

Collection of blood from camels was performed by qualified veterinarians following proper physical restraint of animals to ensure both personnel and animal safety. Livestock owners were explained the study purposes and procedures and upon agreeing to participate, they provided a written consent prior to study procedures and blood collection from their animals. The study received ethical clearance from the Research Board of the Faculty of Veterinary Medicine, University of Khartoum, Sudan. The risk factor information was obtained from the animal owners through the structured questionnaire form, which permitted the use of the blood samples for diagnostic and research purposes. 


\section{Author details}

Molecular Biology Laboratory (MBL), Department of Clinical Medicine, Faculty of Veterinary Medicine, University of Khartoum, P.O. Box 32, Khartoum North, Sudan. ${ }^{2}$ Center for Viral Hemorrhagic Fevers, Al-Neelain Institute of Medical Research (NIMR), Al-Neelain University, Khartoum, Sudan.

Received: 2 December 2015 Accepted: 3 June 2016

Published online: 10 June 2016

\section{References}

1. Aradaib IE, Erickson BR, Karsany MS, Khristova ML, Elageb RM, Khidir IE, Karrar AE, Nichol ST. Rift Valley fever, Sudan. 2007-2010. Emerg Infect Dis. 2013:19:45-52.

2. Shoemaker T, Boulianne C, Vincent MJ, Pezzanite L, Al-Qahtani MM, AlMazrou Y, Khan AS, Rollin PE, Swanepoel R, Ksiazek TG, Nichol ST. Genetic analysis of viruses associated with emergence of Rift Valley fever in Saudi Arabia and Yemen, 2000-2001. Emerg Infect Dis. 2002;8:1415-20.

3. Abd el-Rahim $I H$, Abd el-Hakim U, Hussein M. An epizootic of Rift Valley fever in Egypt in 1997. Rev Sci Tech. 1999;18:741-8.

4. Bird BH, Khristova ML, Rollin PE, Ksiazek TG, Nichol ST. Complete genome analysis of 33 ecologically and biologically diverse Rift Valley fever virus strains reveals widespread virus movement and low genetic diversity due to recent common ancestry. J Virol. 2007;81:2805-16.

5. Madani TA, Al-Mazrou YY, Al-Jeffri MH, Mishkhas AA, Al-Rabeah AM, Turkistani AM, Al-Sayed MO, Abodahish AA, Khan AS, Ksiazek TG, Shobokshi O. Rift Valley fever epidemic in Saudi Arabia: epidemiological, clinical, and laboratory characteristics. Clin Infect Dis. 2003;37:1084-92.

6. Anyamba A, Linthicum KJ, Small J, Britch SC, Pak E, de La Rocque S, et al. Prediction, assessment of the Rift Valley fever activity in east and southern Africa 2006-2008 and possible vector control strategies. Am J Trop Med Hyg. 2010;83:43-51.

7. Al-Afaleq Al, Hussein MF, Al-Naeem AA, Housawi F, GKabati A. Seroepidemiological study of Rift Valley fever (RVF) in animals in Saudi Arabia. Trop Anim Health Prod. 2012:44:1535-9.

8. Adam AA, Karsany MS, Adam I. Manifestations of severe Rift Valley fever in Sudan. Int J Infect Dis. 2010;14:e179-180.

9. Eisa M, Obeid HMR. Rift Valley fever in the Sudan. II. Isolation and identification of the virus from a recent epizootic in Kosti District. Bull Anim Health Prod Afr. 1977;25:349-55.

10. Eisa M, Obeid HMA, El Sawi SA. Rift Valley fever in the Sudan. I. Results on field investigations of the first epizootic in Kosti District, 1973. Bull Anim Health Prod Afr. 1977;25:343-7.

11. McIntosh BM, Russell D, dos Santos I, Gear JH. Rift Valley fever in humans in South Africa. S Afr Med J. 1980:58:803-6.

12. Eisa M. Preliminary survey of domestic animals of the Sudan for precipitating antibodies to Rift Valley fever virus. J Hyg (Lond). 1984;93:629-37.

13. Saleh AS, Mohammed KA, Hassan MM, Bucci TJ, Meegan JM. Antibodies to Rift Valley fever virus in the human population of Sudan. Trans R Soc Trop Med Hyg. 1981;75:129-30.

14. Davies FG. Rift Valley fever in the Sudan. Trans R Soc Trop Med Hyg. 1990;84:141.

15. WHO 2007: Global alert and response, Rift Valley fever in Sudan, update November 7. 2007 [2012 May 1].

16. Hassanain AM, Noureldien W, Karsany MS, Saeed ES, Aradaib IE, Adam I. Rift Valley fever among febrile patients at New Halfa hospital, eastern Sudan. Virol J. 2010;7:e97.

17. Meegan JM, Hoogstraal H, Moussa MI. An epizootic of Rift Valley fever in Egypt in 1977. Vet Rec. 1979;105:124-5.

18. Eisa M, ED K e-S, Shomein AM, Meegan JM. An outbreak of Rift Valley fever in the Sudan-1976. Trans R Soc Trop Med Hyg. 1990;74:417-9.

19. Olaleye OD, Tomori O, Schmitz H. Rift Valley fever in Nigeria: infections in domestic animals. Rev Sci Tech. 1996;15:937-46.

20. Davies FG. Risk of a rift valley fever epidemic at the haj in Mecca, Saudi Arabia. Rev Sci Tech. 2006;25:137-47.

21. Nguku PM, Sharif SK, Mutonga D, Amwayi S, Omolo J, Mohammed O, Farnon EC, Gould CL, Lederman E, Rao C, Sang R, Schnabel D, Feikin DR, Hightower A, Njenga MK, Breiman RF. An investigation of a major outbreak of Rift Valley fever in Kenya: 2006-2007. Am J Trop Med Hyg. 2010;83:5-13.

22. Munyua P, Murithi RM, Wainwright S, Githinji J, Hightower J, Mutonga D, Macharia J, Ithondeka PM, Musaa J, Breiman RF, Bloland P, Njenga MK. Rift Valley fever outbreak in livestock in Kenya, 2006-2007. Am J Trop Med Hyg. 2010:83:58-64.
23. Sang R, Kioko E, Lutomiah J, Warigia M, Ochieng C, O'Guinn M, Lee JS, Koka H, Godsey M, Hoel D, Hanafi H, Miller B, Schnabel D, Breiman RF, Richardson J. Rift Valley fever virus epidemic in Kenya, 2006/2007: the entomologic investigations. Am J Trop Med Hyg. 2010;83:28-37.

24. Jäckel S, Eiden M, El Mamy BO, Isselmou K, Vina-Rodriguez A, Doumbia B, Groschup MH. Molecular and serological studies on the Rift Valley fever outbreak in Mauritania in 2010. Transbound Emerg Dis. 2013;2:31-9.

25. Britch SC, Binepal YS, Ruder MG, Kariithi HM, Linthicum KJ, Anyamba A, Small JL, Tucker CJ, Ateya LO, Oriko AA, Gacheru S, Wilson WC. Rift Valley fever risk map model and seroprevalence in selected wild ungulates and camels from Kenya. PLoS One. 2013;8:e66626.

26. El Mamy AB, Lo MM, Thiongane Y, Diop M, Isselmou K, Doumbia D, Baba MO, El Arbi AS, Lancelot R, Kane Y, Albina E, Cêtre-Sossah C. Comprehensive phylogenetic reconstructions of Rift Valley fever virus: the 2010 northern Mauritania outbreak in the Camelus dromedarius species. Vect Borne Zoo Dis. 2014;14:856-61

27. Swai ES, Sindato C. Seroprevalence of Rift Valley fever virus infection in camels (dromedaries) in northern Tanzania. Trop Anim Health Prod. 2015:47:347-52.

28. Hassan OA, Ahlm C, Sang R, Evander M. The 2007 Rift Valley fever outbreak in Sudan. PLoS Negl Trop Dis. 2011;5(9):e1229.

29. Martin SW, Meek AH, Willeberg P. Veterinary epidemiology: principles and methods. Ames, lowa, USA: lowa State University Press; 1987. p. 45.

30. von Elm E, Altman DG, Egger M, Pocock SJ, Gøtzsche PC, Vandenbroucke JP, STROBE Initiative. The strengthening the reporting of observational studies in epidemiology (STROBE) statement: guidelines for reporting observational studies. Lancet. 2007:370:1453-7.

31. Abdo-Salem S, Gerbier G, Bonnet P, Al-Qadasi M, Tran A, Thiry E, Al-Eryni G, Roger F. Descriptive and spatial epidemiology of Rift valley fever outbreak in Yemen 2000-2001. Ann N Y Acad Sci. 2006;1081:240-2.

32. Aradaib IE, Elageb RM, Abdalla TM, Karrar AE, Karsani MS, Musa HA. mproved diagnosis of Rift Valley fever in clinical samples using Conventional semi-nested reverse transcriptase-PCR. Int J Molec Med Adv Sci. 2008;4:77-81.

33. Rich KM, Wanyoike F. An assessment of the regional and national socio-economic impacts of the 2007 Rift Valley fever outbreak in Kenya. Am J Trop Med Hyg. 2010;83:52-7.

34. Mariner JC, Morrill J, Ksiazek TG. Antibodies to hemorrhagic fever viruses in domestic livestock in Niger: Rift Valley fever and Crimean-Congo hemorrhagic fever. Am J Trop Med Hyg. 1995:53:217-21.

35. Turell MJ, Linthicum KJ, Patrican LA, Davies FG, Kairo A, Bailey CL. Vector competence of selected African mosquito (Diptera: Culicidae) species for Rift Valley fever virus. J Med Entomol. 2008;45:102-8.

36. Anyangu AS, Gould LH, Sharif SK, Nguku PM, Omolo JO, Mutonga D, et al. Risk factors for severe Rift Valley fever infection in Kenya. Am J Trop Med Hyg. 2010;83:14-21.

37. Di Nardo A, Rossi D, Saleh SM, Lejlifa SJ, Hamdi A, Di Gennaro A, Savini G, Thrusfield MV. Evidence of Rift Valley fever seroprevalence in the Sahrawi semi-nomadic pastoralist system, Western Sahara. BMC Vet Res. 2014;10:92.

38. Bird BH, Githinji JWK, Macharia JM, Kasiiti JL, Muriithi RM, Gacheru SG, Musaa JO, Towner JS, Reeder SA, Oliver JB, Stevens TL, Erickson BR, Morgan LT, Khristova ML, Hartman AL, Comer JA, Rollin PE, Ksiazek TG, Nichol ST. Multiple virus lineages sharing recent common ancestry were associated with a large Rift Valley fever outbreak among livestock in Kenya during 2006-2007. J Virol. 2008:82:11152-1166.

39. Carroll SA, Reynes GM, Khristova ML, Andriamandimby SF, Rollin PE, Nichol ST. Genetic evidence for Rift Valley fever outbreaks in Madagascar resulting from virus introductions from the east African mainland rather than enzootic maintenance. J Virol. 2011:85:6162-7.

40. Nderitu L, Lee JS, Omolo J, Omulo S, O'Guinn ML, Hightower AF, Mosha M, Mohamed M, Munyua P, Nganga Z, Hiett Z, Seal B, Feikin DR, Breiman RF, Njenga MK. Sequential Rift Valley fever outbreaks in eastern Africa caused by multiple lineages of the virus. J Infect Dis. 2011;203:655-65. 